Heide, I. van der, Uiters, E., Rademakers, J., Struijs, J.N., Schuit, A.J., Baan, C.A. Associations among health literacy, diabetes knowledge, and self-management behavior in adults with diabetes: results of a dutch cross-sectional study. Journal of Health Communication: 201 19(Suppl. 2), 115-131

\begin{tabular}{|l|l|}
\hline $\begin{array}{l}\text { Postprint } \\
\text { Version }\end{array}$ & 1.0 \\
\hline Journal website & $\frac{\text { http://www.tandfonline.com/doi/abs/10.1080/10810730.2014.936989?url ver=Z3 }}{\underline{9.88-2003 \& r f r} \text { id=ori:rid:crossref.org\&rfr dat=cr pub\%3dpubmed }}$ \\
\hline Pubmed link & $\underline{\text { http://www.ncbi.nlm.nih.gov/pubmed/25315588 }}$ \\
\hline DOI & $10.1080 / 10810730.2014 .936989$
\end{tabular}

This is a NIVEL certified Post Print, more info at http://www.nivel.eu

\title{
Associations Among Health Literacy, Diabetes Knowledge, and Self-Management Behavior in Adults with Diabetes: Results of a Dutch Cross- Sectional Study.
}

IRIS VAN DER HEIDE ${ }^{\text {A }}$, ELLEN UITERS ${ }^{\text {A }}$, JANY RADEMAKERS ${ }^{\mathrm{B}}$, JEROEN N. STRUIJS ${ }^{\text {AC }}$, A. JANTINE SCHUIT ${ }^{\mathrm{AD}}$ \& CAROLINE A. BAAN ${ }^{\mathrm{A}}$

${ }^{a}$ Centre for Nutrition, Prevention and Health Services, National Institute for Public Health and the Environment , Bilthoven, The Netherlands

${ }^{\mathrm{b}}$ Netherlands Institute for Health Services Research (NIVEL), Utrecht, The Netherlands

${ }^{\mathrm{c}}$ Department of Health Policy and Management, Harvard School of Public Health , Boston , Massachusetts, USA

${ }^{d}$ Department of Health Sciences and EMGO Institute for Health and Care Research , VU University Amsterdam , Amsterdam , The Netherlands

\begin{abstract}
Various studies have examined the association between health literacy and selfmanagement behavior, but few have explored ways through which this occurs. The present study examines to what extent health literacy is associated with diabetes self-management behavior and to what extent diabetes knowledge is a mechanism in this association. The study was based on cross-sectional data retrieved from patient registrations and questionnaires completed in 2010. The sample included 1,714 predominantly type 2 diabetes patients, with a mean age of 67 years. Diabetes self-management was indicated by HbA1c level, glucose self-control and self-reported monitoring of glucose levels, physical activity, and smoking. Multilevel analyses were applied based on multiple imputed data. Lower health literacy was significantly associated with less diabetes knowledge, higher HbA1c level, less self-control of glucose level, and less physical activity. Participants with more diabetes knowledge were less likely to smoke and more likely to control glucose levels. Diabetes knowledge was a mediator in the association between health literacy and glucose self-control and between health literacy and smoking. This study indicates that higher health literacy may contribute to participation in certain self-management activities, in some cases
\end{abstract}


Heide, I. van der, Uiters, E., Rademakers, J., Struijs, J.N., Schuit, A.J., Baan, C.A. Associations among health literacy, diabetes knowledge, and self-management behavior in adults with diabetes: results of a dutch cross-sectional study. Journal of Health Communication: 2014 19(Suppl. 2), 115-131

through diabetes knowledge. Diabetes knowledge and health literacy skills may be important targets for interventions promoting diabetes self-management.

Self-management is a core element of diabetes care, in the course of which patients fulfill a significant role in the care for their disease. Adequate self-management can positively affect health outcomes among diabetes patients (Albisser, Harris, Albisser, \& Sperlich, 2001; Williams, McGregor, Zeldman, Freedman, \& Deci, 2004 ) and involves managing the symptoms, treatment, physical and psychosocial consequences and lifestyle changes inherent in living with diabetes (Barlow, Wright, Sheasby, Turner, \& Hainsworth, 2002 ; Wagner et al., 2001). Diabetes selfmanagement can be indicated by various tasks, including glucose monitoring, physical activity, nutritional management, and medication utilization (Fransen, von Wagner, \& Essink-Bot, 2012).

The performance of self-management tasks requires certain skills, such as the ability to understand information on how lifestyle behaviors affect the course of diabetes (von Wagner, Steptoe, Wolf, \& Wardle, 2009 ). Being able to understand healthrelated information is considered one element of the concept of health literacy, which can be defined as the competences that are needed to access, understand, appraise, and apply health-related information (Sørensen et al., 2012 ). Research indicates that lower health literacy is common among those who suffer from a chronic condition, including diabetes (Schillinger et al., 2002 ). Yet, individuals with a chronic illness need to apply health literacy skills on a regular basis, for instance when interpreting blood glucose levels.

Health literacy is not merely considered important for understanding information, but also for generating knowledge regarding health issues (Krathwohl, 2002 ). When information is not understood, for example, it seems unlikely that this information is stored in one's memory to be remembered and used at a later time (Krathwohl, 2002 ). The relation between health literacy and knowledge is also present in the context of diabetes care; lower health literacy is found to be associated with less diabetes knowledge (Al Sayah, Majumdar, Williams, Robertson, \& Johnson, 2013 ; Fransen et al., 2012). Furthermore, studies found that patients with less diabetes knowledge are less likely to perform self-management tasks (Fransen et al., 2012 ).

With respect to the interrelations among health literacy, diabetes knowledge, and self-management, little research has been undertaken. Recently, Osborn, Bains, and Egede (2010) found no evidence for a direct effect of health literacy on diabetes selfcare, based on a sample of 130 type 2 diabetes patients, nor an indirect effect via diabetes knowledge. However, on the basis of the theoretical framework as presented by von Wagner and colleagues (2009), one would expect health literacy to be related to self-management, partly via diabetes knowledge. This framework, developed to guide research on health literacy and health actions, hypotheses that health literacy influences sociocognitive and psychological factors, like knowledge, which, in turn, determine health actions, including disease management (von Wagner et al., 2009 ). Von Wagner and colleagues (2009) argued that it is important for their framework to be tested and possibly revised so that interventions that mitigate the influence of lower health literacy on health related behavior, such as diabetes self-management, are informed. 
Heide, I. van der, Uiters, E., Rademakers, J., Struijs, J.N., Schuit, A.J., Baan, C.A. Associations among health literacy, diabetes knowledge, and self-management behavior in adults with diabetes: results of a dutch cross-sectional study. Journal of Health Communication: 201 19(Suppl. 2), 115-131

In this context, the aim of the present study is to investigate whether diabetes nivel knowledge can account for part of the relation between health literacy and diabetes self-management behavior. We thereby contribute to the knowledge base regarding determinants of diabetes self-management. The focus on diabetes knowledge as a mechanism linking health literacy to diabetes self-management is considered a first step in studying pathways between health literacy and self-management behavior. Our specific research questions are as follows:

1. To what extent is health literacy associated with diabetes knowledge?

2. To what extent is health literacy associated with indicators of self-management behavior?

3. To what extent does diabetes knowledge mediate the association between health literacy and indicators of self-management behavior?

\section{METHOD}

\section{Study Design}

This study was part of a larger observational study performed between January 2008 and June 2010 that focused on disease management programs and related bundled payments (Struijs et al., 2012 ). Details about the design of this study are reported elsewhere (Drewes et al., 2012 ; Struijs et al., 2012 ). For the present study, we used data from June 2009 to June 2010.

\section{Data Collection}

Data were retrieved from general practitioner (GP) registrations, which were on an individual basis linked to survey data that was collected by a questionnaire (Drewes et al., 2012 ). This questionnaire was administered in a random sample of 4265 diabetes patients clustered within a random sample of 78 GP practices. The response rate to the patient questionnaire was $46 \%(n=1,941)$. No information was available on reasons for nonresponse. For 1,714 respondents, questionnaires could be linked to patient medical records; the other 227 were no longer under treatment. All respondents gave informed consent for linking the survey data to their medical records for the purpose of the study.

\section{Main Variables}

\section{Health Literacy}

Health literacy was assessed by Chew's Set of Brief Screening Questions, which is a validated subjective measure of health literacy (Chew et al., 2004 ; Fransen, Van Schaik, Twickler, \& Essink-Bot, 2011 ). The Set of Brief Screening Questions consists of three items: "How confident are you filling out forms by yourself?" (Confident With Forms), "How often do you have someone (like a family member, friend, hospital/clinic worker or caregiver) help you read hospital materials?” (Help Read), and "How often do you have problems learning about your medical condition because of difficulty understanding written information?" (Problems Reading). Responses were scored on a 5-point Likert scale ranging from 0 (always/not at all confident) to 4 (never/extremely confident). Lower scores reflect lower health 
Heide, I. van der, Uiters, E., Rademakers, J., Struijs, J.N., Schuit, A.J., Baan, C.A. Associations among health literacy, diabetes knowledge, and self-management behavior in adults with diabetes: results of a dutch cross-sectional study. Journal of Health Communication: 201 19(Suppl. 2), 115-131

literacy skills (Chew et al., 2004 ; Fransen et al., 2011 ). The mean score on the three items was used in analyses as a continuous variable.

\section{Diabetes Knowledge}

Diabetes knowledge was assessed by the 14 item Diabetes Knowledge Test, which has shown to be a reliable and valid instrument based on data from the United States (Fitzgerald et al., 1998 ). A forward-backward translation procedure was applied and done by the fourth author (J.N.S.) and a specialist in the field of English literature. The minor discrepancies that occurred with the original Diabetes Knowledge Test were discussed and solved during a consensus meeting. The items and answer options are presented in the Appendix. Sum scores were included in the analyses as a continuous variable ranging from 0 (lowest score) indicating little diabetes knowledge to 14 (highest score) indicating much diabetes knowledge. The Dutch version of the Diabetes Knowledge Test is available on request.

\section{Self-Management Behavior}

Self-management behavior was indicated by five variables, which were selected based on previous research and on the GPs' guideline for diabetes care as formulated by the Dutch College of General Practitioners (Sluiter et al., 2012 ). These indicators include glucose self-control, self-reported monitoring of glucose levels, physical activity, smoking, and HbA1c level. Glycemic control (HbA1c level) is the standard marker of diabetes control, and it can be considered an indicator of self-management behavior given that poor glycemic control is associated with a sedentary lifestyle and a poor diet (Davis et al., 2001 ). HbA1c level was obtained from GP registrations (in $\mathrm{mmol} / \mathrm{mol}$ ) and analyzed as a continuous variable. Self-reported smoking behavior (“Are you a smoker?” [yes/no]) was analyzed as a dichotomous variable. Selfreported glucose self-control ("Do you control your blood sugar, for example by the use of an insulin self-injection?" [yes/no]) and self-reported monitoring of glucose levels ("Do you use the glucose diary to register your glucose level?" [yes/no]) were analyzed as dichotomous variables. Physical activity was assessed by self-reported physical activity other than sports ("How often are you involved in active physical activity (other than sports)?” [not at all; 1 to 2 hours a week; 2 to 4 hours a week; 4 to 6 hours a week; more than 6 hours a week]) and self-reported involvement in sports ("How often are you involved in sportive physical activity?" [not at all; up to 2 hours a week; 2 to 4 hours a week; more than 4 hours a week]). To obtain a broader indicator of physical activity, the items measuring physical activity other than sports and involvement in sports were combined, leading to a variable ranging from 0 (no physical activity on a weekly basis) to 7 (more than 6 hours physically active and more than 4 hours of sport on a weekly basis), which was analyzed as a continuous variable and referred to as physical activity.

\section{Other Variables}

Diabetes duration, insulin use, perceived health status, presence of comorbidities, age, education, and sex were included as control variables. Age and diabetes duration were measured in years and analyzed as continuous variables. Education was measured by self-reported highest completed level of education, categorized into low (primary school, lower occupational education, or less), medium (secondary level education), and high (university, higher occupational education, or corresponding 
Heide, I. van der, Uiters, E., Rademakers, J., Struijs, J.N., Schuit, A.J., Baan, C.A. Associations among health literacy, diabetes knowledge, and self-management behavior in adults with diabetes: results of a dutch cross-sectional study. Journal of Health Communication: 2014 19(Suppl. 2), 115-131

education). Insulin use was self-reported and analyzed as a dichotomous variable. The presence of comorbidities was determined through a list of 15 diseases that was derived from the Permanent Survey Living Conditions (Statistics Netherlands, n.d.). Using this list, patients indicated whether they suffered from one or more of 15 diseases in the 12 months before the study (including depression). The presence of comorbidity was then analyzed as a dichotomous variable (no comorbidities vs. one or more comorbidities). Perceived health status was measured with a single item (first item of the Short Form 12). Answer options were given on a 5-point Likert scale and analyzed as a continuous variable (Ware, Kosinski, \& Keller, 1995).

\section{Missing Values}

Missing values on health literacy, diabetes knowledge, and self-management questions varied from 1\% (for glucose self-control) to $12 \%$ (for one Diabetes Knowledge Test item). Missing values were computed, for both patient registration data (i.e., HbA1c) and survey data (i.e., health literacy) using Multivariate Imputation by Chained Equations procedure in R (van Buuren \& GroothuisOudshoorn, 2011 ). Twenty imputation datasets were created. Analyses were performed with the multiple imputed datasets (Janssen et al., 2010 ). The necessary number of iterations for each missing value was 40 based on the Gibbs sampler (van Buuren et al., 2011 ). Results of the analyses on the twenty imputed datasets were pooled by the MIANALYZE procedure in SAS.

\section{Statistical Analysis}

The internal consistency of the Diabetes Knowledge Test was low $(\alpha=.512)$. Since excluding items did not improve the internal consistency, the scores on the fourteen items were combined into sum scores. To answer the research questions, multilevel analyses were performed taking GP practice level into account in order to control for clustering on GP practice level. To answer the first research question, we estimated the associated between health literacy and diabetes knowledge (a-path Figure 1). To answer the second research question, we estimated the association between health literacy and indicators of self-management behavior in five separate analyses, including respectively HbA1c level, physical activity, smoking, glucose self-control, and self-reported monitoring of glucose levels. The analyses were first performed without diabetes knowledge (c-path Figure 1), and secondly including diabetes knowledge (c'-path Figure 1). To answer the third research question, we applied mediation analysis as proposed by MacKinnon, Fairchild, and Fritz (2007 ). Therefore, we examined whether adding diabetes knowledge to the models changed the associations between health literacy and self-management. Second, we estimated the association between diabetes knowledge and each indicator of self-management (b-path Figure 1). Third, the Sobel test was used to estimate the possible mediating role of diabetes knowledge in the association between health literacy and selfmanagement (the significance of $\mathrm{a} * \mathrm{~b}$; Sobel, 1982). The mediation framework as proposed by MacKinnon and colleagues (2007) suggested that potential mediation effects should be analyzed if there is a significant association between the independent variable and the mediator (a-path) and between the mediator and the dependent variable (b-path). All analyses were adjusted for diabetes duration, insulin use, perceived health, presence of one or more comorbidities, age, education, and 
Heide, I. van der, Uiters, E., Rademakers, J., Struijs, J.N., Schuit, A.J., Baan, C.A. Associations among health literacy, diabetes knowledge, and self-management behavior in adults with diabetes: results of a dutch cross-sectional study. Journal of Health Communication: 201 19(Suppl. 2), 115-131

sex. Analyses were performed by using the GLIMMIX procedure in SAS 9.3. Associations were considered significant at $\mathrm{p} \leq .05$.

\section{[FIGURE 1$]$}

\section{RESULTS}

\section{Sample Characteristics}

As to health literacy, $90 \%$ of the respondents had a mean health literacy score higher than 2, implying that most respondents felt confident with filling out forms and perceived little difficulty with understanding and reading information (see Table 1). The mean score on the Diabetes Knowledge Test was 9.2 (SD = 2.2). As to selfmanagement indicators, $66.7 \%$ had an $\mathrm{HbA} 1 \mathrm{c}$ value below $53 \mathrm{mmol} / \mathrm{mol}$.

Furthermore, a minority of the respondents smoked (14.0\%) and a substantial part of the sample controlled (41.8\%) and registered (48.9\%) blood sugar levels by themselves. The mean score on the physical activity scale was $3.0(\mathrm{SD}=1.8)$, which indicated several possibilities, including the following: patients were involved in sports for more than 4 hours a week; patients were physically active in ways other than sports for 4 to 6 hours a week; or patients combined sports up to 4 hours a week with 1 to 4 hours of other types of physical activity.

\section{[TABLE 1.]}

\section{Health Literacy and Patient Characteristics}

Table 1 indicates some noticeable differences in characteristics between patients with lower health literacy and higher health literacy. Compared with those with higher health literacy, those with lower health literacy showed a relative large proportion of respondents aged 75 year or older (47.1\% vs. $23.6 \%)$ and who obtained a low level of education (79.3\% vs. 41.2\%). The mean score on the Diabetes Knowledge Test was lower among those with lower health literacy $(\mathrm{M}=8.3)$ than among those with higher health literacy $(M=9.3)$. As to glycemic control, $57.9 \%$ of patients with lower health literacy showed an HbA1c level lower than $53 \mathrm{mmol} / \mathrm{mol}$ compared with $67.6 \%$ of those with higher health literacy.

\section{Association Between Health Literacy and Diabetes Knowledge}

Mean scores on the Diabetes Knowledge Test for those with higher and lower health literacy (see Table 1) suggested an association between health literacy and diabetes knowledge (a-path Figure 1). Multilevel analysis, adjusted for diabetes duration, insulin use, perceived health status, presence of comorbidities, age, education and sex, confirmed that lower health literacy was significantly associated with less diabetes knowledge $(\mathrm{B}=0.27, \mathrm{SE}=0.07$; not tabulated).

\section{Association Between Health Literacy and Self-Management Behavior}

As to the direct association between health literacy and indicators of diabetes selfmanagement behavior (c-path Figure 1), no significant associations were found between health literacy and self-reported monitoring of glucose levels and smoking 
Heide, I. van der, Uiters, E., Rademakers, J., Struijs, J.N., Schuit, A.J., Baan, C.A. Associations among health literacy, diabetes knowledge, and self-management behavior in adults with diabetes: results of a dutch cross-sectional study. Journal of Health Communication: 201 19(Suppl. 2), 115-131

(not tabulated). Lower health literacy was significantly associated with higher HbA1c level $(\mathrm{B}=-0.71, \mathrm{SE}=0.33)$ and less physical activity $(\mathrm{B}=0.14, \mathrm{SE}=0.06)$. Those with lower health literacy also had higher odds for no self-control of glucose level than those with lower health literacy (OR = 0.7, 95\% CI [0.58, 0.87]; not tabulated). These findings were adjusted for diabetes duration, insulin use, perceived health status, presence of comorbidities, age, education, and sex. In analyses including diabetes knowledge (c'-path Figure 1), lower health literacy was again not associated with smoking and self-reported monitoring of glucose levels but was significantly associated with higher HbA1c level $(B=-0.76, \mathrm{SE}=0.32)$, less physical activity $(\mathrm{B}=0.13, \mathrm{SE}=0.06)$ and no self-control of glucose level $(\mathrm{OR}=$ 0.74, 95\% CI [0.60, 0.91]; see Table 2).

\section{[TABLE 2.]}

\section{Association Between Diabetes Knowledge and Self-Management Behavior}

Analyses of the association between diabetes knowledge and self-management (bpath Figure 1) revealed that more diabetes knowledge was associated with lower odds for no self-control of glucose level (OR $=0.87,95 \%$ CI $[0.81,0.93]$ ) and lower odds for smoking $(\mathrm{OR}=0.90,95 \%$ CI $[0.84,0.97]$; see Table 2$)$. Diabetes knowledge was not associated with HbA1c level, physical activity or self-reported monitoring of glucose levels (see Table 2). These analyses were adjusted for diabetes duration, insulin use, perceived health status, presence of comorbidities, age, education, sex, and health literacy. Figure 2 summarizes the associations found between health literacy, diabetes knowledge and each of the self-management indicators.

\section{[FIGURE 2 ]}

\section{Mediating Role of Diabetes Knowledge}

The Sobel test indicated that diabetes knowledge was a mediator between health literacy and glucose self-control $(\mathrm{p}<.01)$ and between health literacy and smoking $(\mathrm{p}<.05)$.

\section{DISCUSSION}

This study investigated the interrelations among health literacy, diabetes knowledge, and self-management behavior. The results show that those with lower health literacy have lower scores on the Diabetes Knowledge Test, are less physically active, less likely to perform glucose self-control, and have higher HbA1c levels than those with higher health literacy. The results also show that there are no differences between those with lower and higher health literacy regarding smoking and self-reported monitoring of glucose levels. This means that the association between health literacy and self-management is not straightforward and depends on the type of selfmanagement behavior, which nuances the theoretical model as proposed by von Wagner and colleagues (2009). The relation between health literacy and knowledge, as conceptualized by this model, is reflected by our findings, although the direction of this relation could not be determined because of our cross-sectional study design. 
Heide, I. van der, Uiters, E., Rademakers, J., Struijs, J.N., Schuit, A.J., Baan, C.A. Associations among health literacy, diabetes knowledge, and self-management behavior in adults with diabetes: results of a dutch cross-sectional study. Journal of Health Communication: 2014 19(Suppl. 2), 115-131

Furthermore, the results indicate that patients with less diabetes knowledge are more likely to smoke and less likely to control their glucose levels themselves, but that there is no difference between less or more knowledgeable patients when it comes to self-reported monitoring of glucose levels, physical activity and HbA1c level. This implies that diabetes knowledge may be more important for certain tasks than for others, or that patients are less aware of the importance of physical activity compared with the importance of glucose level control or smoking behavior regardless of their diabetes knowledge.

Because there are theoretical grounds to expect that having less diabetes knowledge can partly account for the relation between lower health literacy and less selfmanagement behavior (von Wagner et al., 2009 ), we examined to what extent diabetes knowledge clarifies the association between health literacy and selfmanagement behavior. Less diabetes knowledge partly accounts for the association between having lower health literacy and being less likely to control glucose levels. This suggests that increasing diabetes knowledge among those with lower health literacy may lead to increases in self-control of glucose levels, although we cannot infer causation from our study design. This also yields for smoking; diabetes knowledge seems to be a binding factor between health literacy and smoking behavior. Diabetes knowledge can, on the other hand, not explain the association between health literacy and physical activity, or the association between health literacy and HbA1c. This implies that increasing diabetes knowledge among patients with lower health literacy will probably not lead to increased physical activity, or improved HbA1c levels among this group.

In light of previous studies, the associations we found between health literacy and certain self-management indicators (self-control of glucose level, physical activity and $\mathrm{HbA1c}$ ) are not supported by a number of other studies (Bains \& Egede, 2011 ; Kim, Love, Quistberg, \& Shea, 2004 ; Mbaezue et al., 2010 ; Osborn et al., 2010 ). As to HbA1c, this may be due to differences in operationalization: Studies that adopted a dichotomous operationalization of HbA1c found no association between health literacy and HbA1c level (Bains et al., 2011 ; Powell, Hill, \& Clancy, 2007 ; Schillinger et al., 2002 ). Therefore, we repeated our analyses including HbA1c as dichotomous variable $(\mathrm{HbA} 1 \mathrm{c}<53$ vs. HbA1c $\geq 53)$. This did not lead to significant associations, implying that differences between our study and other studies could partly be attributed to the way HbA1c is operationalized.

Differences between our findings and findings of others could also be due to sample size, as most studies reporting on the association between health literacy and diabetes self-management behavior were based on relatively small samples $(\mathrm{n}=92$ to $\mathrm{n}=$ 398; Fransen et al., 2012). Furthermore, the instruments we used to measure health literacy and self-management behavior differ from the instruments used by others (Fransen et al., 2012 ). The Rapid Estimate of Adult Literacy in Medicine (Davis et al., 1991 ) and the Test of Functional Health Literacy in Adults (Parker, Baker, Williams, \& Nurss, 1995 ), instruments mostly used in previous studies, reflect pronunciation and reading comprehension, which may lead to different estimations of health literacy compared with our estimation. As to self-management behavior, the Summary of Diabetes Self-Care Activities Measure was often adopted in previous studies (Fransen et al., 2012 ). The Summary of Diabetes Self-Care Activities Measure assesses self-care behavior in the past 7 days, where in our study, the selfmanagement measures are not time bound, except for physical activity. Therefore, 
Heide, I. van der, Uiters, E., Rademakers, J., Struijs, J.N., Schuit, A.J., Baan, C.A. Associations among health literacy, diabetes knowledge, and self-management behavior in adults with diabetes: results of a dutch cross-sectional study. Journal of Health Communication: 2014 19(Suppl. 2), 115-131

the number of patients that performs self-management may be relatively high in our study compared with studies that used the Summary of Diabetes Self-Care Activities Measure.

To summarize, health literacy and diabetes knowledge can be relevant determinants of self-management behavior depending on the type of self-management task. However, health literacy and diabetes knowledge are not the only factors that determine how a person interprets self-management tasks. There are theoretical and empirical grounds to expect that factors such as self-efficacy, attitudes, motivation, perceived susceptibility and severity and social influences are determinants as well (Fransen et al., 2012 ; von Wagner et al., 2009 ). Furthermore, self-management behavior may vary by patients' health care providers, as some health care providers may promote self-management behavior to a greater extent than others. Although our data showed that the proportion of people performing self-management tasks varies to some extent according to GP practice, we have too little information on the support that was given by the various GPs for a proper insight into this variation and to make any inferences regarding the influence of GP support in self-management behavior.

\section{Strengths and Limitations}

Main strengths of the present study include its quantification of the presumed relation between health literacy and diabetes self-management through diabetes knowledge. The results of this study thereby contribute to the foundation of theories concerning determinants of self-management behavior. Other strengths of this study include the relatively large sample size and the use of state-of-the-art statistical techniques for data analysis.

This study is, however, also subject to some limitations. First, a written questionnaire may have limitations when studying health literacy because nonparticipation is likely among patients who have difficulty reading and writing. Our results may therefore reflect an overestimation of diabetes patients' health literacy skills and an underestimation of its association with self-management behavior.

Regarding the health literacy instrument, the Set of Brief Screening Questions, it is short, easy-to-complete and validated among those with a chronic illness (Chew et al., 2004 ; Fransen et al., 2011 ). The drawback of the Set of Brief Screening Questions is that it provides a limited measure of health literacy, since it was developed as a screening instrument for clinical practise. Compared to more objective measures of health literacy, such as the Newest Vital Sign or the Rapid Estimate of Adult Literacy in Medicine, the Set of Brief Screening Questions can lead to an overestimation of adequate health literacy (Fransen et al., 2011 ). We therefore may have underestimated the number of patients with lower health literacy as would have been indicated by objective health literacy measures. The use of an objective health literacy measure may show stronger associations with diabetes selfmanagement than a subjective health literacy measure, which implies that our findings may be toning down associations that are present in real life.

Another limitation is that to our knowledge the Diabetes Knowledge Test has not yet been validated for use in The Netherlands. Furthermore, the internal consistency of the Diabetes Knowledge Test as indicated in the present study was relatively low ( $\alpha$ $=.512$ ) compared with an American validation study ( $\alpha=.7$; Fitzgerald, 1998 ).

Nevertheless, the fact that the Diabetes Knowledge Test's outcomes are in line with 
Heide, I. van der, Uiters, E., Rademakers, J., Struijs, J.N., Schuit, A.J., Baan, C.A. Associations among health literacy, diabetes knowledge, and self-management behavior in adults with diabetes: results of a dutch cross-sectional study. Journal of Health Communication: 201 19(Suppl. 2), 115-131

our expectations is reassuring; higher diabetes knowledge is associated with higher level of education, longer diabetes duration, and higher health literacy. A more important limitation opposed to the low internal consistency of the Diabetes Knowledge Test, is the lack of test-retest information on this version of the Diabetes Knowledge Test, which would provide a proper indication of reliability. Furthermore, the Diabetes Knowledge Test does not measure specific knowledge regarding smoking and self-reported monitoring of glucose levels, although we related diabetes knowledge to both behaviors. We presupposed that knowledge regarding various topics of diabetes self-management would provide an indication of the general knowledge base of diabetes patients. The association we found between more diabetes knowledge and being less likely to smoke provides some support for this assumption.

Fifth, the present study covered two domains of diabetes self-management: blood glucose monitoring and physical activity (Fransen et al., 2012 ). However, health literacy could affect the other two domains as well, namely nutritional management and medication utilization. Given the differences in results regarding the two domains that were studied, research on the other two domains is needed in order to obtain a complete picture of the relation between health literacy and diabetes selfmanagement.

\section{CONCLUSIONS}

The present study indicates that higher health literacy may contribute to involvement in certain self-management activities, in some cases through diabetes knowledge. Diabetes knowledge and health literacy skills may be important targets for interventions promoting diabetes self-management. Increasing health literacy skills among diabetes patients as well as adapting interventions to be suitable for patients of all literacy skills may help support patients in the management of their diabetes.

\section{ACKNOWLEDGMENT}

The authors acknowledge the contribution of Dr. H. Drewes of the National Institute for Public Health and the Environment, who performed the multiple imputation procedure.

\section{APPENDIX: DiABETES KNOWLEDGE TEST}

\section{Questions}

1. The diabetes diet is

a. the way most American people eat

b. a healthy diet for most people*

c. too high in carbohydrate for most people

d. too high in protein for most people

2. Which of the following is highest in carbohydrate?

a. Baked chicken 
Heide, I. van der, Uiters, E., Rademakers, J., Struijs, J.N., Schuit, A.J., Baan, C.A. Associations among health literacy, diabetes knowledge, and self-management behavior in adults with diabetes: results of a dutch cross-sectional study. Journal of Health Communication: 201 19(Suppl. 2), 115-131

b. Swiss cheese

c. Baked potato*

d. Peanut butter

3. Which of the following is highest in fat?

a. Low fat milk*

b. Orange juice

c. Corn

d. Honey

4. Which of the following is a "free food"?

a. Any unsweetened food

b. Any dietetic food

c. Any food that says "sugar free" on the label

d. Any food that has less than 20 calories per serving*

5. Glycosylated hemoglobin (hemoglobin $\mathrm{Al}$ ) is a test that is a measure of your average blood glucose level for the past:
a. day
b. week
c. $6-10$ weeks*
d. 6 months

6. Which is the best method for testing blood glucose?

a. Urine testing

b. Blood testing*

c. Both are equally good

7. What effect does unsweetened fruit juice have on blood glucose?
a. Lowers it
b. Raises it*
c. Has no effect

8. Which should not be used to treat low blood glucose?

a. 3 hard candies

b. $1 / 2$ cup orange juice

c. 1 cup diet soft drink*

d. 1 cup skim milk

9. For a person in good control, what effect does exercise have on blood glucose?
a. Lowers it*
b. Raises it
c. Has no effect

10. Infection is likely to cause:

a. an increase in blood glucose*

b. a decrease in blood glucose

c. no change in blood glucose 
Heide, I. van der, Uiters, E., Rademakers, J., Struijs, J.N., Schuit, A.J., Baan, C.A. Associations among health literacy, diabetes knowledge, and self-management behavior in adults with diabetes: results of a dutch cross-sectional study. Journal of Health Communication: 201 19(Suppl. 2), 115-131

11. The best way to take care of your feet is to:

a. look at and wash them each day*

b. massage them with alcohol each day

c. soak them for one hour each day

d. buy shoes a size larger than usual

12. Eating foods lower in fat decreases your risk for:
a. nerve disease
b. kidney disease
c. heart disease*
d. eye disease

13. Numbness and tingling may be symptoms of:
a. kidney disease
b. nerve disease*
c. eye disease
d. liver disease

14. Which of the following is usually not associated with diabetes:
a. vision problems
b. kidney problems
c. nerve problems
d. lung problems*

*Correct answer.

Note. Based on Fitzgerald et al. (1998).

Notes.

${ }^{a}$ As diagnosed by the physician or not.

${ }^{\mathrm{b}}$ Range $=0$ (lowest score) to 14 (highest score).

c $53 \mathrm{mmol} / \mathrm{mol}=7.0 \%$.

${ }^{\mathrm{d}}$ Range $=0$ (no physical activity on a weekly basis) to 7 (more than 4 hours of sport and more than 6 hours of nonsportive physical activity on a weekly basis).

a Extreme values $(n=9)$ were excluded from this analysis. 
Heide, I. van der, Uiters, E., Rademakers, J., Struijs, J.N., Schuit, A.J., Baan, C.A. Associations among health literacy, diabetes knowledge, and self-management behavior in adults with diabetes: results of a dutch cross-sectional study. Journal of Health Communication: 201 19(Suppl. 2), 115-131

\section{REFERENCES.}

1. Albisser , A. M. , Harris , R. I. , Albisser , J. B. , \& Sperlich , M. ( 2001 ). The impact of initiatives in education, self-management training, and computer-assisted self-care on outcomes in diabetes disease management . Diabetes Technology and Therapeutics , 11 , $571-579$.

2. Al Sayah , F. , Majumdar , S. R. , Williams , B. , Robertson , S. , \& Johnson , J. A. ( 2013 ). Health literacy and health outcomes in diabetes: A systematic review . Journal of General Internal Medicine, $28,444-452$.

3. Bains , S. S. , \& Egede , L. E. ( 2011 ). Associations between health literacy, diabetes knowledge, self-care behaviors, and glycemic control in a low income population with type 2 diabetes. Diabetes Technology and Therapeutics , 13 , $335-341$

4. Barlow , J. , Wright , C. , Sheasby , J. , Turner , A. , \& Hainsworth , J. ( 2002 ). Selfmanagement approaches for people with chronic conditions: A review. Patient Education and Counseling , $48,177-187$

5. Chew , L. D. , Bradley , K. A. , \& Boyko , E. J. ( 2004 ). Brief questions to identify patients with inadequate health literacy . Family Medicine , 36 , $588-594$.

6. Davis , T. C. , Crouch, M. A. , Long , S. W. , Jackson, R. H. , Bates , P. , George , R. B. , \& Bairnsfather , L. E. ( 1991 ). Rapid assessment of literacy levels of adult primary care patients. Family Medicine , 23, $433-435$.

7. Davis , T. C. , Dolan , N. C. , Ferreira, M. R. , Tomori , C. , Green , K. W. , Sipler , A. M. , \& Bennett, C. L. ( 2001 ). The role of inadequate health literacy skills in colorectal cancer screening . Cancer Investigation , $19,193-200$.

8. Drewes , H. W. , de Jong-van Til , J. T. , Struijs , J. N. , Baan , C. A. , Tekle , F. B. , Meijboom , B. R. , \& Westert , G. P. ( 2012 ). Measuring chronic care management experience of patients with diabetes: PACIC and PACIC+validation . International Journal of Integrated Care , 1 , e194.

9. Fitzgerald , J. T. , Funnell , M. M. , Hess , G. E. , Barr , P. A. , Anderson , R. M. , Hiss , R. G. , \& Davis , W. K. ( 1998 ). The reliability and validity of a brief Diabetes Knowledge Test Diabetes Care , $21,706-710$.

10. Fransen, M. P. , Van Schaik, T. M. , Twickler, T. B. , \& Essink-Bot, M. L. ( 2011 ). Applicability of internationally available health literacy measures in The Netherlands . Journal of Health Communication , 16 , $134-149$.

11. Fransen, M. P. , von Wagner , C. , \& Essink-Bot, M. L. ( 2012 ). Diabetes selfmanagement in patients with low health literacy: Ordering findings from literature in a health literacy framework. Patient Education and Counseing , 88, $44-53$.

12. Janssen , K. J. , Donders , A. R. , Harrell , F. E. , Jr. , Vergouwe , Y. , Chen , Q. , Grobbee , D. E. , \& Moons , K. G. (2010). Missing covariate data in medical research: To impute is better than to ignore. Journal of Clinical Epidemiology , 63, 721-727.

13. Kim , S. , Love , F. , Quistberg , D. A. , \& Shea , J. A. ( 2004 ). Association of health literacy with self-management behavior in patients with diabetes . Diabetes Care , 27 , $2980-2982$

14. Krathwohl , D. R. ( 2002 ). A revision of Bloom's Taxonomy: An overview . Theory Into Practice , $41,212-264$.

15. MacKinnon , D. P. , Fairchild , A. J. , \& Fritz , M. S. ( 2007 ). Mediation analysis . Annual Review of Psychology , 58 , 593 - 614 . doi: 10.1146/annurev.psych.58.110405.085542

16. Mbaezue , N. , Mayberry , R. , Gazmararian , J. , Quarshie , A. , Ivonye , C. , \& Heisler , M. ( 2010 ). The impact of health literacy on self-monitoring of blood glucose in patients with diabetes receiving care in an inner-city hospital . Journal of the National Medical Association , $102,5-9$.

17. Osborn , C. Y., Bains , S. S. , \& Egede , L. E. ( 2010 ). Health literacy, diabetes selfcare, and glycemic control in adults with type 2 diabetes . Diabetes Technology and Therapeutics , $12,913-919$.

18. Parker , R. M. , Baker , D. W. , Williams , M. V. , \& Nurss , J. R. ( 1995 ). The Test of Functional Health Literacy in Adults: A new instrument for measuring patients' literacy skills . Journal of General Internal Medicine , 10 , 537 - 541 
Heide, I. van der, Uiters, E., Rademakers, J., Struijs, J.N., Schuit, A.J., Baan, C.A. Associations among health literacy, diabetes knowledge, and self-management behavior in adults with diabetes: results of a dutch cross-sectional study. Journal of Health Communication: 201 19(Suppl. 2), 115-131

19. Powell , C. K. , Hill , E. G. , \& Clancy , D. E. ( 2007 ). The relationship between health literacy and diabetes knowledge and readiness to take health actions. Diabetes Education , $33,144-151$.

20. Schillinger , D. , Grumbach , K. , Piette , J. , Wang , F. , Osmond , D. , Daher , C. , ... Bindman, A. B. ( 2002 ). Association of health literacy with diabetes outcomes . JAMA, $288,475-482$.

21. Sluiter , A. C. , Van Wijland, J. J. , Arntzenius , A. B. , Bots , A. F. E. , Dijkhorst-Oei , L. T. , Van der Does , F. E. E. , ... Van Balen, J. A. M. ( 2012 ). L andelijke Transmurale Afspraak Diabetes mellitus type 2 [National Transmural Agreement diabetes mellitus type 2] . Huisarts Wet , 55 , S1 - S12 . Retrieved from https://www.nhg.org/dutch-collegegeneral-practitioners

22. Sobel , M. E. ( 1982 ). Asymptotic confidence intervals for indirect effects in structural equation models. Sociological Methodology , 13 , $290-312$.

23. Sørensen , K. , Van den Broucke , S. , Fullnam , J. , Doyle , G. , Pelikan , J. , Slonska , Z. , \& Brand , H. ( 2012 ). Health literacy and public health: A systematic review and integration of definitions and models. BMC Public Health , 12,80 .

24. Statistics Netherlands. (n.d.) . Permanent Onderzoek Leefsituatie. [Continuous Netherlands Health Interview Survey] . Retrieved from http://www.cbs.nl/NR/rdonlyres/36331B4C-A693-4260A9CB4336AF7F63CB/0/POLStoelichting_versie29_09_05.pdf

25. Struijs, J. N. , De Jong-van Til , J. T., Lemmens , L. C. , Drewes, H. W. , De Bruin, S. R. , \& Baan , C. A. ( 2012 ). Experimenting with a bundled payment system for diabetes care in the Netherlands: results after three years. Bilthoven, The Netherlands : National Institute for Public Health and the Environment . Retrieved from http://www.rivm.nl/bibliotheek/rapporten/260013002.pdf .

26. van Buuren , S. , \& Groothuis-Oudshoorn , K. ( 2011 ). MICE: Multivariate Imputation by Chained 455 Equations in R. Journal of Statistical Software , 45, $1-67$.

27. von Wagner , C. , Steptoe , A. , Wolf , M. S. , \& Wardle , J. ( 2009 ). Health literacy and health actions: A review and a framework from health psychology. Health Education and Behavior , $36,860-877$.

28. Wagner, E. H. , Austin , B. T. , Davis , C. , Hindmarsh , M. , Schaefer, J. , \& Bonomi , A. ( 2001 ). Improving chronic illness Care: Translating evidence into action . Health Affairs , $20,64-78$.

29. Ware , J. E. , Kosinski , M. , \& Keller , S. D. ( 1995 ). SF-12: How to score the SF-12 Physical and Mental Health Summary Scales (), 2nd ed. . Boston, MA : The Health Institute, New England Medical Center .

30. Williams , G. C. , McGregor , H. A. , Zeldman , A. , Freedman , Z. R. , \& Deci , E. L. ( 2004 ). Testing a self-determination theory process model for promoting glycemic control through diabetes self-management . Health Psychology , $11,58-66$. 
Heide, I. van der, Uiters, E., Rademakers, J., Struijs, J.N., Schuit, A.J., Baan, C.A. Associations among health literacy, diabetes knowledge, and self-management behavior in adults with diabetes: results of a dutch cross-sectional study. Journal of Health Communication: 2014 19(Suppl. 2), 115-131

\section{TABLES AND FIGURES}

Figure 1. Conceptual model of the studied associations between health literacy, diabetes knowledge, and self-management. DKT=Diabetes Knowledge Test; SBSQ=Set of Brief Screening Questions.

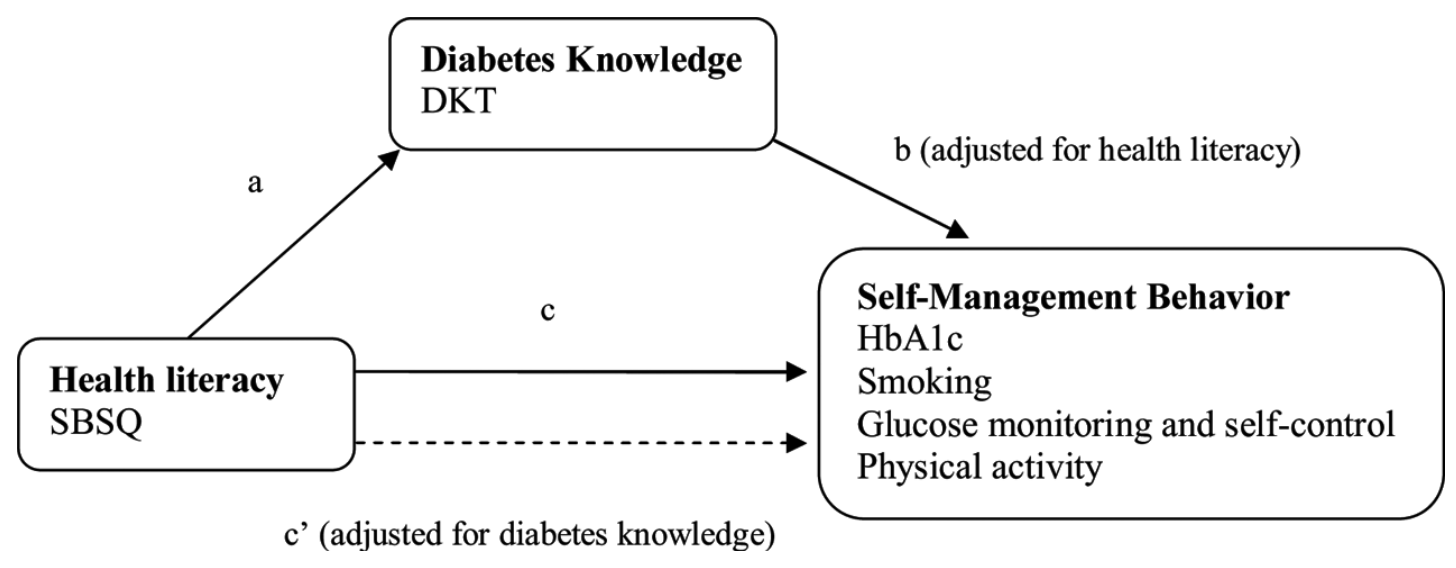


Table 1. Sample characteristics

\begin{tabular}{|c|c|c|c|c|c|c|}
\hline \multirow[b]{3}{*}{ Characteristic } & & & \multicolumn{4}{|c|}{ Health literacy mean score (range $=0$ to 4 ) } \\
\hline & \multicolumn{2}{|c|}{ Total $(N=1,714)$} & \multicolumn{2}{|c|}{$\begin{array}{c}\leq 2 \text { (lower health literacy) } \\
(n=167)\end{array}$} & \multicolumn{2}{|c|}{$\begin{array}{c}>2 \text { (higher health literacy) } \\
(n=1547)\end{array}$} \\
\hline & $\%$ & $n$ & $\%$ & $n$ & $\%$ & $n$ \\
\hline Female & 49.6 & 850 & 64.2 & 107 & 48.0 & 743 \\
\hline \multicolumn{7}{|l|}{ Age (years) } \\
\hline$\leq 24$ & 0.3 & 5 & 0.6 & 1 & 0.3 & 4 \\
\hline$\overline{25}-54$ & 14.5 & 249 & 18.9 & 16 & 15.0 & 233 \\
\hline $55-64$ & 27.6 & 473 & 13.6 & 23 & 29.1 & 451 \\
\hline $65-74$ & 31.7 & 542 & 29.2 & 49 & 31.9 & 494 \\
\hline$\geq 75$ & 25.9 & 444 & 47.1 & 79 & 23.6 & 365 \\
\hline \multicolumn{7}{|l|}{ Level of education } \\
\hline Low & 44.9 & 770 & 79.3 & 132 & 41.2 & 638 \\
\hline Middle & 39.7 & 680 & 19.4 & 32 & 41.9 & 648 \\
\hline High & 15.4 & 264 & 1.3 & 2 & 16.9 & 262 \\
\hline \multicolumn{7}{|l|}{ Diabetes type } \\
\hline Type 1 & 2.2 & 38 & 1.7 & 3 & 2.3 & 35 \\
\hline Type 2 & 97.8 & 1,676 & 98.3 & 164 & 97.7 & 1,512 \\
\hline \multicolumn{7}{|l|}{ Diabetes duration (years) ${ }^{a}$} \\
\hline$\leq 3$ & 26.5 & 454 & 27.4 & 46 & 26.4 & 408 \\
\hline$\overline{4}-10$ & 45.2 & 775 & 39.4 & 66 & 45.8 & 709 \\
\hline$\geq 10$ & 28.3 & 485 & 33.2 & 55 & 27.8 & 430 \\
\hline \multicolumn{7}{|l|}{ Medication use } \\
\hline Oral diabetic medication (pills) & 72.0 & 1,228 & 69.2 & 115 & 71.9 & 1,113 \\
\hline Insulin & 25.5 & 438 & 37.7 & 63 & 24.2 & 375 \\
\hline \multicolumn{7}{|l|}{ Self-reported general health status } \\
\hline Good/very good/excellent & 94.4 & 1,617 & 85.2 & 142 & 95.3 & 1,475 \\
\hline Poor/moderate & 5.6 & 97 & 14.8 & 25 & 4.7 & 73 \\
\hline \multicolumn{7}{|l|}{ Comorbidity } \\
\hline Discordant comorbidity & 44.2 & 757 & 41.7 & 69 & 44.4 & 688 \\
\hline Concordant comorbidity & 5.4 & 93 & 4.2 & 7 & 5.6 & 86 \\
\hline Discordant and concordant comorbidity & 19.7 & 337 & 30.8 & 51 & 18.5 & 286 \\
\hline
\end{tabular}

붕은 녹 
Table 1. Continued

Health literacy mean score (range $=0$ to 4 )

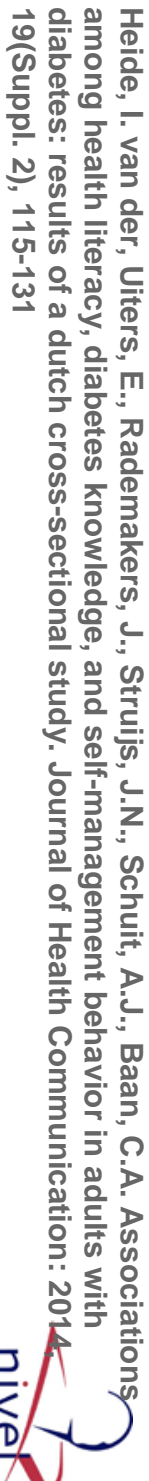

\begin{tabular}{|c|c|c|c|c|c|c|}
\hline \multirow[b]{2}{*}{ Characteristic } & \multicolumn{2}{|c|}{ Total $(N=1,714)$} & \multicolumn{2}{|c|}{$\begin{array}{c}\leq 2 \text { (lower health literacy) } \\
(n=167)\end{array}$} & \multicolumn{2}{|c|}{$\begin{array}{l}>2 \text { (higher health literacy) } \\
\qquad(n=1547)\end{array}$} \\
\hline & $\%$ & $n$ & $\%$ & $n$ & $\%$ & $n$ \\
\hline Diabetes Knowledge Test, $M(S D)^{b}$ & 9.2 & 2.2 & 8.3 & 2.2 & 9.3 & 2.2 \\
\hline $\mathrm{HbAlc}$ level $<53 \mathrm{mmol} / \mathrm{mol}^{c}$ & 66.7 & 1,137 & 57.9 & 96 & 67.6 & 1,041 \\
\hline Excluded because of extreme values & & 9 & & 2 & & 7 \\
\hline Smoking & 14.0 & 238 & 13.8 & 23 & 13.9 & 215 \\
\hline Glucose monitoring & & & & & & \\
\hline Glucose self-control & 41.8 & 717 & 40.8 & 68 & 41.9 & 649 \\
\hline Self-reported monitoring of glucose levels & 48.9 & 839 & 53.4 & 89 & 48.4 & 750 \\
\hline Physical activity, $M(S D)^{d}$ & 3.0 & 1.8 & 2.5 & 1.8 & 3.1 & 1.8 \\
\hline
\end{tabular}

${ }^{a}$ As diagnosed by the physician or not.

${ }^{b}$ Range $=0$ (lowest score) to 14 (highest score)

$53 \mathrm{mmol} / \mathrm{mol}=7.0 \%$

Range $=0$ (no physical activity on a weekly basis) to 7 (more than 4 hours of sport and more than 6 hours of nonsportive physical activity on a weekly basis). 
Table 2. Associations between health literacy and self-management indicators (c' path in Figure 1) and between diabetes knowledge and self-management indicators (b path in Figure 1)

\begin{tabular}{|c|c|c|c|c|c|c|}
\hline Variable & $\begin{array}{c}\mathrm{HbA} \mathrm{c}^{a} \\
B(S E)\end{array}$ & $\begin{array}{l}\text { Physi } \\
\text { activ } \\
B(S\end{array}$ & $\begin{array}{l}\text { ical } \\
\text { vity } \\
S E)\end{array}$ & $\begin{array}{l}\text { No glucose self-control (vs. } \\
\text { glucose self-control) } \\
\text { OR }(95 \% \mathrm{CI})\end{array}$ & $\begin{array}{c}\text { No monitoring of glucose levels (vs. } \\
\text { monitoring glucose levels) } \\
\text { OR ( } 95 \% \mathrm{CI})\end{array}$ & $\begin{array}{l}\text { Smoking (vs. not } \\
\text { smoking) } \\
\text { OR }(95 \% \mathrm{CI})\end{array}$ \\
\hline Diabetes duration & $0.14(0.05)$ & -0.0002 & $(0.008)$ & $0.94(0.91-0.97)$ & $0.99(0.97-1.02)$ & $0.97(0.94-1.01)$ \\
\hline Insulin use & $7.72(0.64)$ & -0.13 & $(0.11)$ & $0.02(0.01-0.03)$ & $0.08(0.06-0.12)$ & $1.15(0.78-1.69)$ \\
\hline Perceived health & $0.33(0.38)$ & -0.67 & $(0.07)$ & $0.78(0.63-0.97)$ & $0.95(0.79-1.14)$ & $1.06(0.85-1.33)$ \\
\hline $\begin{array}{l}\text { Presence of } \\
\text { comorbidity }\end{array}$ & $-0.12(0.56)$ & -0.17 & $(0.10)$ & $1.01(0.74-1.36)$ & $0.99(0.75-1.29)$ & $1.11(0.79-1.55)$ \\
\hline Age & $-0.06(0.02)$ & -0.02 & $(0.004)$ & $1.03(1.01-1.04)$ & $0.99(0.98-1.00)$ & $0.96(0.95-0.97)$ \\
\hline \multicolumn{7}{|l|}{ Level of education } \\
\hline Medium & $0.15(0.56)$ & 0.12 & $(0.10)$ & $1.14(0.82-1.58)$ & $1.14(0.86-1.51)$ & $0.79(0.56-1.11)$ \\
\hline High & $-1.10(0.80)$ & -0.15 & $(0.14)$ & $1.04(0.66-1.63)$ & $1.89(1.24-2.88)$ & $0.58(0.35-0.97)$ \\
\hline Male & $-1.55(0.49)$ & -0.20 & $(0.09)$ & $1.17(0.89-1.55)$ & $1.25(0.98-1.59)$ & $0.74(0.55-1.00)$ \\
\hline $\begin{array}{l}\text { Health literacy } \\
\text { (c'-coefficient) }\end{array}$ & $-0.76(0.33)$ & 0.13 & $(0.06)$ & $0.74(0.60-0.91)$ & $1.00(0.84-1.19)$ & $0.99(0.81-1.22)$ \\
\hline $\begin{array}{l}\text { Diabetes knowledge } \\
\text { (b-coefficient) }\end{array}$ & $0.13(0.11)$ & 0.04 & $(0.02)$ & $0.87(0.81-0.93)$ & $0.94(0.89-1.00)$ & $0.90(0.84-0.97)$ \\
\hline
\end{tabular}

Note. Presented estimates are adjusted for all included covariates. Significant associations (at $p<.05$ ) appear in boldface.

${ }^{a}$ Extreme values $(n=9)$ were excluded from this analysis.

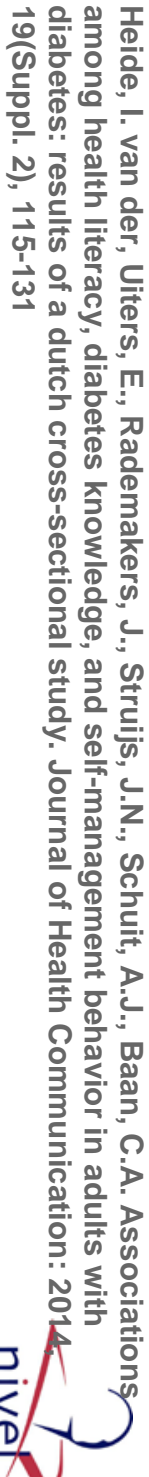


Heide, I. van der, Uiters, E., Rademakers, J., Struijs, J.N., Schuit, A.J., Baan, C.A. Associations among health literacy, diabetes knowledge, and self-management behavior in adults with diabetes: results of a dutch cross-sectional study. Journal of Health Communication: 201 19(Suppl. 2), 115-131

Figure 2. Associations among health literacy, diabetes knowledge, and selfmanagement activities, adjusted for diabetes diagnose duration, insulin use, perceived health, the presence of comorbidities, age, level of education, and sex in all steps, indicating a significant positive association (b), a significant negative association (-), or no significant association (0).
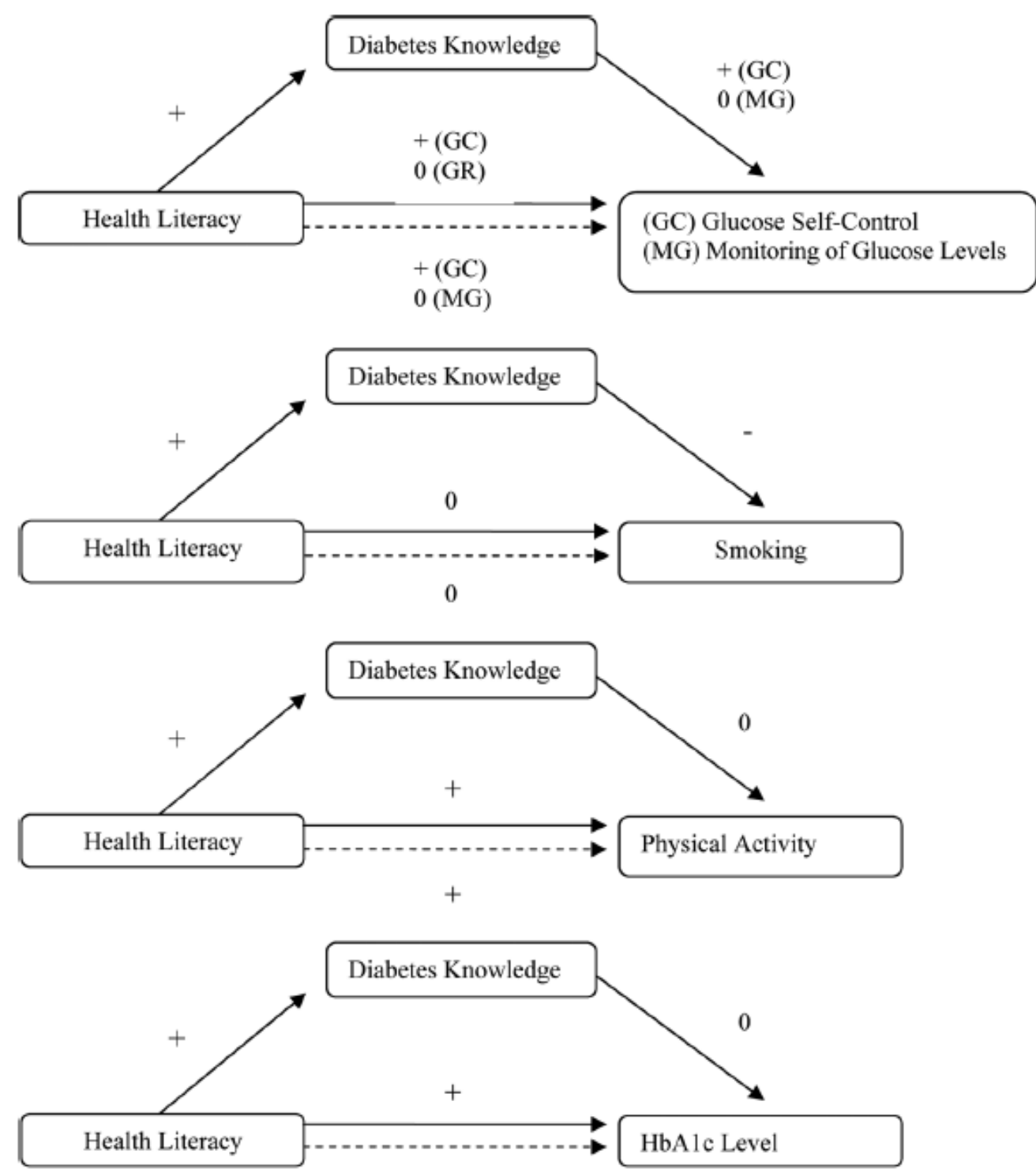